\title{
Tubercular Meningitis with Acute Inflammatory Demyelinating Polyneuropathy-Trigger or Chance
}

\author{
Siba Prasad Dalai ${ }^{1} \quad$ Shobhitendu Kabi ${ }^{1} \quad$ Nikhil R. Arve ${ }^{1} \quad$ Vujwal R. Kakollu $^{1}$ \\ ${ }^{1}$ Department of Medicine, IMS and SUM Hospital, Bhubaneswar, \\ Address for correspondence Siba Prasad Dalai, MD, Department \\ Odisha, India \\ of Medicine, IMS and SUM Hospital, Bhubaneswar, Odisha, India \\ (e-mail: drsibadalai@gmail.com).
}

J Neurosci Rural Pract 2019;10:545-547

\begin{abstract}
Keywords

- Guillain-Barre

syndrome

- nerve conduction

study

- plasmapheresis

- tuberculosis

Tuberculosis being a global pandemic causes an array of neurological presentations ranging from tuberculoma, meningitis, radiculomyelitis, brain abscess, and so on. Association of Guillain-Barre syndrome with tuberculosis has been reported five to six times in the past. The authors report a case of a young female with tubercular meningitis on antitubercular therapy and steroids who went on to develop acute areflexic quadriparesis and diagnosed as a case of acute motor sensory axonal neuropathy variety of acute inflammatory demyelinating polyneuropathy (AIDP) who responded positively to plasmapheresis. The authors present the first case of an association between tubercular meningitis and subsequent development of AIDP.
\end{abstract}

\section{Introduction}

Guillain-Barre syndrome (GBS) also known as acute inflammatory demyelinating polyneuropathy (AIDP) is generally seen following Campylobacter jejuni, mycoplasma, chlamydia, influenza, cytomegalovirus (CMV), Epstein-Barr virus (EBV) infections, and sometimes following vaccination. ${ }^{1}$ Its incidence is quite rare about $1-2 / 100,000$ population which increases with age. Men are affected 1.5 times more than women. ${ }^{2}$ Cerebrospinal fluid (CSF) analysis and electrodiagnostic testing are of diagnostic value in establishing the diagnosis of GBS, except in the early phase of GBS where both can be normal. ${ }^{3}$

Tuberculosis being a global pandemic causes a multitude of presentations. Neurological manifestations range from tuberculoma, meningitis, radiculomyelitis, brain abscess, etc. ${ }^{4}$ Acute demyelinating polyneuropathy is classically not described in the literature as a manifestation of tuberculosis.

The first reported incidence of coexistence of tuberculosis and GBS goes back to $1983 .{ }^{5}$ Although a few case reports have been published highlighting the association of tuberculosis with GBS, ${ }^{6-10}$ not a single case of tubercular meningitis associated with GBS has been published so far. Here, we report a case of a young female presenting as tubercular meningitis who went on to develop areflexic quadriparesis and was diagnosed through electrodiagnostic tests as acute motor sensory axonal neuropathy (AMSAN) variety of GBS and responded favorably to antitubercular therapy (ATT) and plasmapheresis combined.

\section{Case Report}

A 24-year-old female presented to the emergency department with complaints of low-grade intermittent fever and headache for last 10 days that were associated with nausea, vomiting, and diplopia for last 2 days. She had no history of antecedent diarrhea, upper respiratory tract infection, recent vaccination, weight loss, hemoptysis, past history of tuberculosis, or any contact with a case of active tuberculosis in the past. On examination, there were no meningeal signs, plantar response was bilateral flexor, power was normal in all 4 limbs, deep tendon reflexes were normal, and there was no sensory deficit. There was bilateral lateral rectus palsy. Fundoscopy revealed early papilledema. Noncontrast computed tomography scan of brain was normal. A provisional diagnosis of meningitis was made and cerebrospinal fluid (CSF) study was planned. On the same day of admission, she had one episode of generalized tonic-clonic seizure. Lumbar puncture revealed straw-colored fluid with total cell count of 243 with $96 \%$ lymphocytes, glucose level of $36.1 \mathrm{mg} / \mathrm{dL}$, protein level of $79.1 \mathrm{mg} / \mathrm{dL}$, and adenosine deaminase level of $43 \mathrm{mg} / \mathrm{dL}$. Ziehl-Neelsen stain for acid fast bacilli was negative. Cartridge-based nucleic acid amplification test for CSF sample was sent that came out to be positive. Viral markers (herpes simplex virus, CMV, and EBV) were negative. A provisional diagnosis of tubercular meningitis was made, and the patient was put on isoniazid, rifampicin, pyrazinamide, 
streptomycin, and steroids on first postadmission day. Tests for malarial parasite, and immunoglobulin $\mathrm{M}$ for scrub typhus, were negative. CSF, blood, stool, and urine cultures were negative. There was no evidence of malignancy in either CSF or peripheral blood smear. Triple $\mathrm{H}$ status for human immunodeficiency virus (HIV), hepatitis $B$, and hepatitis $C$ were negative. Patient became afebrile after 4 days of starting ATT, and steroids was steadily improving with therapy.

On the 7th postadmission day, she felt mild tingling sensation over both feet following which she developed sudden-onset weakness of the right lower limb that progressed to left lower limb and ascended to truncal muscles on the same day following which she was unable to ambulate or get up from her bed. Repeat neurological examination revealed nonresponsive bilateral plantar reflex with absent bilateral ankle and knee jerks with diminished bicep and triceps reflexes. Power was 0/5 bilaterally around ankle and knee joint and $2 / 5$ around hip joint. Upper extremity strength was $4 / 5$ bilaterally for biceps and deltoids. There was no sensory involvement. Bladder and bowel were not involved. There were no meningeal signs. Magnetic resonance imaging (MRI) brain and spine with magnetic resonance venography (MRV) were done the next day that was normal. On 8th postadmission day, her upper limb power decreased to $3 / 5$ bilaterally around shoulder and elbow joints. There was no bulbar involvement. Single breath count (SBC) was 14 , and pulse rate increased to 142/min. Vital capacity was $18 \mathrm{~mL} / \mathrm{kg}$ as measured by preintubation spirometry. In view of impending respiratory paralysis, she was intubated.

Nerve conduction study (NCS) was done in bilateral median, ulnar, tibial, peroneal, and sural nerves on the same day. NCS revealed decreased conduction velocity in the left peroneal and tibial nerves; nonrecordable compound motor action potentials in the right median, ulnar, tibial, and peroneal nerves; nonrecordable tracing from bilateral superficial peroneal and sural nerves; prolonged F-wave latency in the left tibial and peroneal nerves; and nonrecordable F-wave latency in the right peroneal nerve. Overall, the NCS was suggestive of asymmetrical sensorimotor-mixed (demyelinating and axonal) polyneuropathy affecting the tested nerves of bilateral lower limbs more than upper limbs. A repeat CSF study was done on 9 th postadmission day that revealed total cell count of 54 with $60 \%$ lymphocytes, glucose level of 60.4 $\mathrm{mg} / \mathrm{dL}$, and protein level of $77.4 \mathrm{mg} / \mathrm{dL}$.

In view of acute-onset areflexic paraplegia with supporting electrophysiologic studies, a diagnosis of AIDP/GBS was made using Brighton criteria (level 2 of diagnostic certainty). ${ }^{11}$ As she was already on ATT and steroids, plasmapheresis was started on 9th day of admission. Over the next 4 days, plasma exchange of 200 to $250 \mathrm{~mL}$ of plasma per kilogram weight in five sessions (40-50 mL/kg per session), she gradually had improved muscle strength of $3 / 5$ in her lower limbs. She was extubated on day 14 of admission. She was discharged on day 18 of admission with a power of $3 / 5$ in her lower limbs, bilateral plantar flexor, diminished ankle and knee reflex, and SBC of 25. A diagnosis of AIDP (AMSAN) with tubercular meningitis was given, and ATT and steroids were continued. She was followed up after 2 months in the outpatient department. The power improved to $4 / 5$ in both upper limbs but remained at $3 / 5$ in the left lower limb and $4 / 5$ in the right lower limb. A repeat NCS revealed asymmetrical mixed polyneuropathy (demyelinating more than axonal). A diagnosis of chronic inflammatory demyelinating polyneuropathy with tubercular meningitis was made in view of response to ATT, steroids, and plasmapheresis.

\section{Discussion}

In our case, patient initially presented as a typical case of tubercular meningitis with fever, headache, altered sensorium, and seizures. While on the course of ATT and steroids, the patient improved for a short period of time (mostly due to steroids) followed by development of areflexic quadriparesis that on electrodiagnostic studies supported the diagnosis of GBS (Brighton criteria-level 2 of diagnostic certainty). ${ }^{11}$ The quadriparesis improved substantially with plasmapheresis further supporting the diagnosis of GBS. Although there was a possibility of isoniazid-induced neuropathy in this patient, even after continuation of isoniazid, the neurological recovery was substantial with plasmapheresis, and sensory symptoms were conspicuously absent. We did not discontinue ATT at any point in the entire duration of treatment in this patient. Critical illness polyneuropathy was not considered in differential diagnosis as the patient had improved with ATT and was weaned easily from the ventilator after 5 days without significant disability or compromised quality of life. As the onset was acute, without any memory deficits or altered mental status, without any focal central nervous system findings, MRI and MRV brain being normal, and as the patient developed weakness while on treatment with steroids, the differential diagnosis of autoimmune encephalitis was not considered at that point of time, and hence, CSF for autoimmune panel was not sent. ${ }^{12}$

The peculiarity of this case is that the patient while on active treatment for tubercular meningitis became afebrile symptomatically due to steroids, sensorium improved for a short period of time, and then, while still on ATT, she suddenly developed quadriparesis which again subsided with prompt diagnostic evaluation of AMSAN variety of GBS and timely plasmapheresis. Such a temporal relationship between patient's symptoms and development of gradual ascending areflexic quadriparesis responding to plasmapheresis and electrodiagnostic studies suggesting mixed demyelinating and axonal sensorimotor neuropathy (AMSAN variety of GBS) is unlikely to be due to mere chance. Serial NCS at 2 months of follow-up remained consistent with AMSAN variety of GBS.

As it is well known, the pathogenesis of GBS is immune mediated; some delay in cell-mediated immunity or some form of molecular mimicry leading to demyelination and axonal damage might be a well-reasoned explanation to hypothesize Mycobacterium tuberculosis as a trigger for GBS. Among all the cases reported previously, two more cases were of AMSAN variety ${ }^{6,9,10}$ only one case was treated with plasmapheresis, ${ }^{10}$ and not a single case of tubercular meningitis had developed GBS during the course of the disease (-Table 1). 
Table 1 Summary of reported cases of tuberculosis and Guillain-Barre syndrome

\begin{tabular}{|c|c|c|c|c|}
\hline Author-year & GBS variety & Tuberculosis & Treatment given & Recovery \\
\hline $\begin{array}{l}\text { Vyravanathan and } \\
\text { Senanayake } 1983^{5}\end{array}$ & Not specified & Pulmonary & ATT only & Complete \\
\hline $\begin{array}{l}\text { Soehardy et al } \\
2005^{6}\end{array}$ & AMSAN & Pulmonary & ATT and IVIG & Complete \\
\hline $\begin{array}{l}\text { de la Torre et al } \\
2010^{7}\end{array}$ & AMAN & Extrapulmonary (lymph node) & ATT and IVIG & Complete \\
\hline Taha and Tee $2012^{8}$ & Not specified & Pulmonary & ATT and IVIG & Complete \\
\hline $\begin{array}{l}\text { Canham and Iseman } \\
2014^{9}\end{array}$ & AMSAN & $\begin{array}{l}\text { Pulmonary with pericardial } \\
\text { effusion }\end{array}$ & ATT and IVIG & $\begin{array}{l}\text { Residual weakness } \\
\text { present }\end{array}$ \\
\hline Mohta et al $2017^{10}$ & AMSAN & $\begin{array}{l}\text { Disseminated (lymph node, } \\
\text { pleural, and pericardial } \\
\text { effusion) }\end{array}$ & $\begin{array}{l}\text { ATT, steroids, and } \\
\text { plasmapheresis }\end{array}$ & $\begin{array}{l}\text { Complete with } \\
\text { constrictive } \\
\text { pericarditis }\end{array}$ \\
\hline Current case 2018 & AMSAN & $\begin{array}{l}\text { Extrapulmonary (tuberculous } \\
\text { meningitis) }\end{array}$ & $\begin{array}{l}\text { ATT, steroids, and } \\
\text { plasmapheresis }\end{array}$ & $\begin{array}{l}\text { Residual weakness } \\
\text { present }\end{array}$ \\
\hline
\end{tabular}

Abbreviations: AMAN, acute motor axonal neuropathy; AMSAN, acute motor and sensory axonal neuropathy; ATT, antitubercular therapy; IVIG, intravenous immunoglobulin.

\section{Conclusion}

In the midst of a tubercular pandemic, our case highlights the possibility of $M$. tuberculosis as an etiological agent or probably a trigger for GBS, hence obviating the need for further investigation, evaluation, and research.

\section{Funding}

None.

\section{Conflict of Interest}

None declared.

\section{References}

1 Gorson KC, Ropper AH, Guillain-Barré syndrome (acute inflammatory demyelinating polyneuropathy) and related disorders. In: Piccione EA, Salame K, Katirji B, eds. Neuromuscular Disorders in Clinical Practice. New York: Springer; 2014: 573-603

2 van Doorn PA, Ruts L, Jacobs BC. Clinical features, pathogenesis, and treatment of Guillain-Barré syndrome. Lancet Neurol 2008;7(10):939-950

3 Burns TM, Guillain-Barré syndrome. Seminars in Neurology. Vol. 28. Number 2. New York: Thieme; 2008 152-167

4 Cherian A, Thomas SV. Central nervous system tuberculosis. Afr Health Sci 2011;11(1):116-127
5 VyravanathanS, Senanayake N. Guillain-Barré syndrome associated with tuberculosis. Postgrad Med J 1983;59(694):516-517

6 Soehardy Z, Yuhanisa A, Thein SS, et al. AMSAN variant of Guillain Barre syndrome progressing to chronic inflammatory demyelinating polyneuropathy in a patient with Marfan's syndrome and pulmonary tuberculosis. Med J Malaysia 2005;60(5):655-656

7 de la Torre RG, Morís G, Martínez DP, Montes IC. Guillain-Barré syndrome, tuberculosis and inflammatory bowel disease: a multiple association. Int Arch Med 2010;3:15

8 Taha AA, Tee KH. Guillain-Barré syndrome associated with pulmonary tuberculosis. BMJ Case Rep 2012;2012:bcr0120125484

9 Canham EM, Iseman MD. Guillain-Barré syndrome related to pulmonary tuberculosis. Ann Am Thorac Soc 2014;11(5):855-857

10 Mohta S, Soneja M, Vyas S, Khot W. Tuberculosis and Guillain-Barre syndrome: a chance association? Intractable Rare Dis Res 2017;6(1):55-57

11 Sejvar JJ, Kohl KS, Gidudu J, et al. Brighton Collaboration GBS Working Group. Guillain-Barré syndrome and Fisher syndrome: case definitions and guidelines for collection, analysis, and presentation of immunization safety data. Vaccine 2011;29(3):599-612

12 Graus F, Titulaer MJ, Balu R, et al. A clinical approach to diagnosis of autoimmune encephalitis. Lancet Neurol 2016;15(4):391-404 